This is the peer reviewed version of the following article: Wei Liu, Danny Haubold, Bogdan Rutkowski, Martin Oschatz, RenéHübner, Matthias Werheid, Christoph Ziegler, Luisa Sonntag, Shaohua Liu, Zhikun Zheng, Anne-Kristin Herrmann, Dorin Geiger, Bürgehan Terlan, Thomas Gemming, Lars Borchardt, Stefan Kaskel, Aleksandra Czyrska-Filemonowicz and Alexander Eychmüller (2016). Selfsupporting Hierarchical Porous PtAg Alloy Nanotubular Aerogels as Highly Active and Durable Electrocatalysts. Chemistry of Materilas, 2016, Vol.28 (18), pp 6477-6843, which has been published in final form at DOI: 10.1021/acs.chemmater.6b01394.

\title{
Self - supporting Hierarchical Porous PtAg Alloy Nanotubular Aerogels as Highly Active and Durable Electrocatalysts
}

Wei Liu, ${ }^{*} \dagger$ Danny Haubold, $\uparrow$ Bogdan Rutkowski, $\ddagger$ Martin Oschatz,§ RenéHuibner,\| Matthias Werheid, $\dagger$

Christoph Ziegler, $\uparrow$ Luisa Sonntag, $\uparrow$ Shaohua Liu, $\uparrow$ Zhikun Zheng, $\uparrow$ Anne-Kristin Herrmann, $\uparrow$

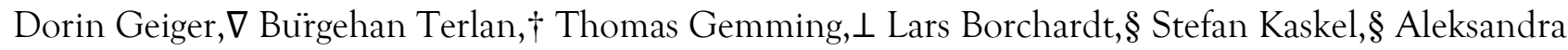

Czyrska-Filemonowicz $\ddagger$ and Alexander Eychmuller* $†$

†Physical Chemistry and Center for Advancing Electronics Dresden (cfaed), TU Dresden, Bergstrasse 66b, 01062 Dresden, Germany

$\ddagger$ Faculty of Metals Engineering and Industrial Computer Science \& International Centre of Electron

Microscopy for Material Science, AGH University of Science and Technology, Al. A. Mickiewicza 30, 30-059 Krakow, Poland

§Inorganic Chemistry, TU Dresden, Bergstrasse 66, 01062 Dresden, Germany

॥Helmholtz-Zentrum Dresden - Rossendorf, Institute of Ion Beam Physics and Materials Research, Bautzner Landstraße 400, 01328 Dresden, Germany

LIFW Dresden, Helmholtzstraße 20, 01069 Dresden, Germany

$\nabla$ Electron Microscopy Group of Material Science, University of Ulm, Albert-Einstein-Allee 11, 89081 Ulm, Germany 


\begin{abstract}
Developing electrocatalysts with low cost, high activity, and good durability is urgently demanded for the wide commercialization of fuel cells. By taking advantage of nanostructure engineering, we fabricated PtAg nanotubular aerogels (NTAGs) with high electrocatalytic activity and good durability via a simple galvanic replacement reaction between the in situ spontaneous gelated Ag hydrogel and the Pt precursor. The PtAg NTAGs have hierarchical porous network features with primary networks and pores from the interconnected nanotubes of the aerogel and secondary networks and pores from the inter-connected thin nanowires on the nanotube surface, and show very high porosities and large specific surface areas. Due to the unique structure, the PtAg NTAGs exhibit greatly enhanced electrocatalytic activity towards formic acid oxidation, reaching 19 times higher metal based mass current density as compared to the commercial Pt black. Furthermore, the PtAg NTAGs show outstanding structural stability and electrochemical durability during the electrocatalysis. Noble metal based NTAGs are promising candidates for applications in electrocatalysis not only for fuel cells, but also for other energy related systems.
\end{abstract}


Nanostructure engineering plays a vital role in nanotechnology. Porous metallic nanomaterials have attracted considerable interest in both research and industry, among which metallic aerogels are very promising materials due to their large surface areas and high porosities. ${ }^{1,2} \mathrm{Up}$ to now, the construction of metallic aerogels with metal backbones has been realized by nanosmelting of hybrid polymer-m etal oxide aerogels or by the direct sol-gelm ethod.:-15 For example, Leventis obtained Fe, Co, Ni, Sn, and Cu aerogels by using the nanosmelting method, and some of them show promising applications as explosives and thermites. ${ }^{3.6}$ However, the precise control of the fine nanostructure and composition of the aerogels by this method still remains limited. Recently, our group developed direct sol-gelm ethods, ether via a twostep gelation process or via a spontaneous one-step gelation process, and prepared mono- or multimetallic aerogels of various compositions containing $\mathrm{Pt}, \mathrm{Pd}, \mathrm{Au}, \mathrm{Ag}$ and $\mathrm{Ni}^{2,7-13}$ These metallic aerogels have three dimensional (3D) nanowire or nanochain network-like morphologies, and have very large specific surface areas and high porosities. Notably, they have shown excellent performances as electrocatalysts with both high catalytic activity and durability for alcohol oxidation ${ }^{8,13}$ and oxygen reduction reaction (ORR) ${ }^{9}$ which are important reactions in fuel cells or metal-air batteries. The outstanding performances of metal aerogels in the aforementioned applications stimulate great interest in enriching the diversity of the metallic aerogels where nanostructure engineering may play an eminent role and in extending their applications.

The wide commercialization of fuel cells requires developing electrocatalysts taking into account their durability alongside their cost and activity. ${ }^{16,17}$ However, this still remains a great challenge. Beside our efforts discussed above, improving the activity and durability of electrocatalysts can be realized via the following routes: 1) by manipulating the structure at the atomic level via constructing Pt-skin, core-shell or alloy structures, or hybrid metal heterostructures; ${ }^{16,18-21} 2$ ) by synthesizing unconventionally shaped $\mathrm{Pt}$ nanocrystals with well-defined and high-index facets; ${ }^{22,23} 3$ ) by using supporting materials more corrosionproof than carbon or forming self-supporting catalysts; ${ }^{17,24} 4$ ) by creating one dimensional (1D) materials like nanowires (NWs) and nanotubes (NTs), or fabricating comprehensive materials combining multiple length scales. ${ }^{20,25-28}$ For example, $\mathrm{Pt}$ nanotubes ${ }^{20}$ and $\mathrm{Pt}_{3} \mathrm{Ni}$ nanoframes ${ }^{27}$ have shown outstanding electrocatalytic activity and durability as ORR catalysts, owning to their unique characteristics such as 1D nanotubular morphology, 3D molecular accessibility, and self-supporting structure. Despite this, the extension of these favorable nanostructures and correspondingly transferring/magnifying their excellent activities into macroscale via forming a metal aerogel remains unexplored.

Herein, we aim to take the advantage of nanostructure engineering and integrate $1 \mathrm{D}$ metal NWs with the NT geometry and further extend this to 3D aerogel networks to form hierarchical porous nanotubular metallic aerogels. PtAg nanotubular aerogels (NTAGs) have been generated via the facile galvanic replacement between the in situ spontaneous gelated $\mathrm{Ag}$ hydrogel and the $\mathrm{Pt}$ precursor $\mathrm{H}_{2} \mathrm{PtCl}_{6}$. The PtAg NTAGs display high porosities and large specific surface areas, and have shown excellent electrocatalytic activity toward formic acid oxidation and long lasting electrochemical and structural durability.

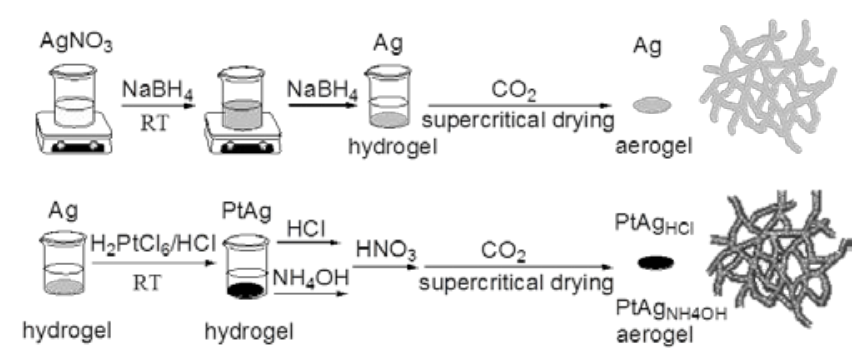

Scheme 1. Schematic illustration on the synthesis of the $\mathrm{PtAg}_{\mathrm{HCl}}$ and $\mathrm{PtAg}_{\mathrm{NH} 4 \mathrm{OH}}$ nanotubular aerogels.

A schematic illustration on the preparation of the PtAg NTAGs is given in Scheme 1. 


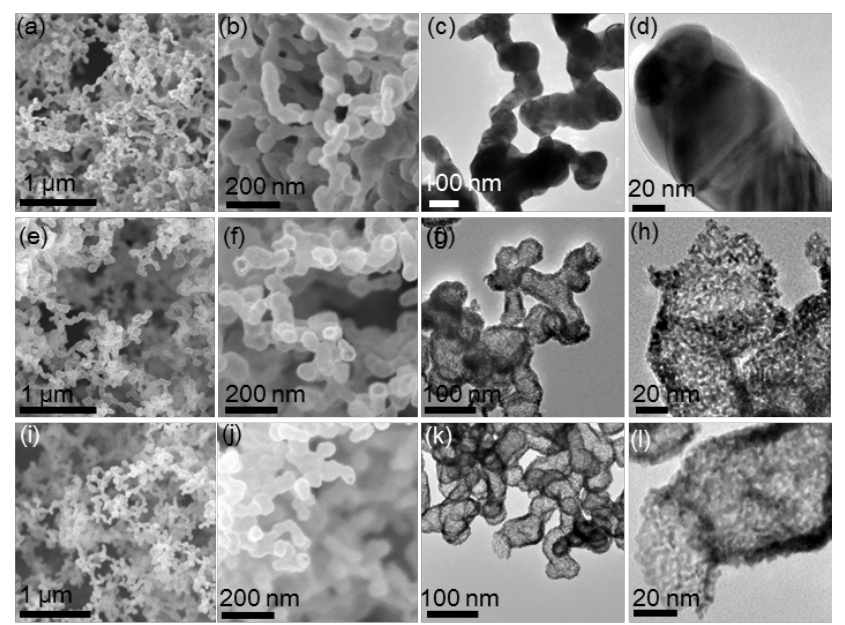

Figure 1. SEM (a, b, e, f, i, j) and TEM images (c, d, g, h, k, l) of the Ag aerogel (a-d), PtAg $\mathrm{HCl}(\mathrm{e}-\mathrm{h})$ and $\mathrm{PtAg}_{\mathrm{NH} 4 \mathrm{OH}}(\mathrm{i}-\mathrm{l})$ NTAGs.

Figure 1 shows scanning electron microscopy (SEM) and transmission electron microscopy (TEM) images of the Ag aerogel and the $\mathrm{PtAg}_{\mathrm{HCl}}$ and $\mathrm{PtAg}_{\mathrm{NH} 4 \mathrm{OH}}$ NTAGs. In contrast to the solid nanowire interconnected network structure of the $\mathrm{Ag}$ aerogel, the $\mathrm{PtAg}_{\mathrm{HCl}}$ and $\mathrm{PtAg}_{\mathrm{NH} 4 \mathrm{OH}}$ NTAGs show both hierarchical porous structures and hierarchical network structures. The nanotubes (shell thickness of $\sim 7$ $10 \mathrm{~nm}$ ) are interconnected with each other, forming the primary network of the PtAg NTAGs. On the nanotube surface some very thin nanowires (diameter of $\sim 2 \mathrm{~nm}$ ) are interconnected with each other, forming a secondary network. The pores of the PtAg NTAGs are composed of hollow cavities of the nanotubes, very small pores surrounding the secondary network on the nanotube surface, and the widely distributed pores from the primary network of

the aerogel.

High resolution TEM (HRTEM) images and the corresponding Fast Fourier Transform (FFT) (Figure S1) reveal that the PtAg NTAGs are highly crystalline with face centered cubic $(\mathrm{fcc})$ polycrystalline structure. X-ray powder diffraction (XRD) characterization further confirms the fcc crystalline structure of the NTAGs (Figure S2). There is only one set of fcc diffraction patterns for both the PtAg NTAGs, their respective reflection positions shift towards smaller angles and their unit cell parameters are larger with respective to the $\mathrm{Pt}$ black, indicating the alloying of $\mathrm{Pt}$ with $\mathrm{Ag}$ and a lattice expansion due to alloying. ${ }^{29}$ Additionally, a set of sharp reflections is also observed in the $\mathrm{PtAg}_{\mathrm{HCl}}$ NTAG, indicating the presence of a detectable cubic phase of $\mathrm{AgCl}$ (JCPDS file: 31-1238) in it. ${ }^{30}$

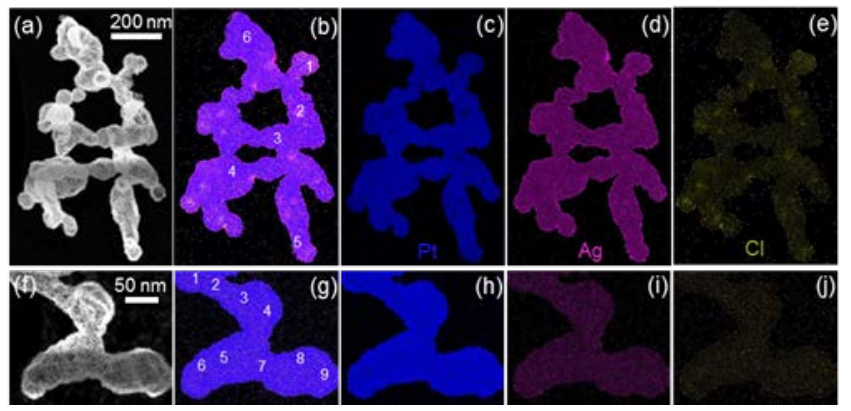

Figure 2. STEM-HAADF images $(\mathrm{a}, \mathrm{f})$ and $\mathrm{Ag}$, Pt and Cl STEM-EDX elemental maps (b-e, g-j) of the $\mathrm{PtAg}_{\mathrm{HCl}}(\mathrm{a}-\mathrm{e})$ and $\mathrm{PtAg} \mathrm{NH}_{4 \mathrm{OH}}(\mathrm{f}-\mathrm{j})$ NTAGs.

High-angle annular dark-field (HAADF) scanning transmission electron microscopy (STEM) as well as energy-dispersive X-ray spectroscopy (EDX) were further utilized to characterize the spatial elemental distribution in the PtAg NTAGs (Figure 2 and Table S1). The PtAg ${ }_{\mathrm{HCl}}$ NTAG is composed of Pt, Ag, and 
$\mathrm{Cl}$ with the $\mathrm{Ag}$ and $\mathrm{Cl}$ distributed over the entire nanotubular networks and the Pt occupying most of the nanotube surfaces, confirming the XRD results in that the Pt and $\mathrm{Ag}$ form an alloy. The average contents of $\mathrm{Pt}, \mathrm{Ag}$, and $\mathrm{Cl}$ of the $\mathrm{PtAg}_{\mathrm{HCl}}$ NTAG determined from the relatively uniform positions (position 3, 4, 5, 6 in Figure $2(\mathrm{~b})$ and Table S1) are $59.5 \pm 1.4$ at\%, $33.7 \pm 0.2$ at\%, and $6.7 \pm 1.3$ at $\%$, respectively. Overall the distribution of $\mathrm{Ag}$ and $\mathrm{Cl}$ is not fully uniform as it shows a higher content in some localized positions where less $\mathrm{Pt}$ is found (e.g. position 1, $\mathrm{Pt} 37.8$ at\%, $\mathrm{Ag} 43.5$ at\%, $\mathrm{Cl} 18.7$ at\%). This indicates the existence of $\mathrm{AgCl}$ residues on the $\mathrm{PtAg}_{\mathrm{HCl}}$ nanotube surface with a certain degree of accumulation at some localized positions. The deviations from the otherwise uniform elemental distribution in the $\mathrm{PtAg}_{\mathrm{HCl}}$ NTAG can either be due to the formation of the unique chemical structure of this aerogel under the synthetic conditions, or caused by the accumulation of $\mathrm{AgCl}$ at specific sites during the 2 s plasma cleaning of the TEM grid before the STEM measurement. For the PtAg $\mathrm{NH}_{4 \mathrm{OH}} \mathrm{NTAG}$, it is composed of $\mathrm{Pt}(69.7 \pm 2.8$ at\%), $\mathrm{Ag}(20.9 \pm 1.8$ at $\%)$, and $\mathrm{Cl}(9.1 \pm 2.2$ at $\%)$. The relatively uniform distribution of $\mathrm{Pt}$ and Ag together with the XRD results indicates the formation of PtAg alloy also in this aerogel. As seen from the photographs during the PtAg aerogel preparation in Figure Sxxx, despite the huge macroscale $3 \mathrm{D}$ porous network structure, the galvanic replacement reaction took place uniformly around the whole hydrogel, no hetero-nanostructure formed independent of the reaction time, the amount of $\mathrm{H}_{2} \mathrm{PtCl}_{6}$ and the shape of the $\mathrm{Ag}$ hydrogel, which is different from the $\mathrm{CdSe} / \mathrm{Ag}_{2} \mathrm{Se}$ gel of hetereo-nanostructures produced by partial cation exchange. J. Am. Chem. Soc. 2009, 131, 2800-2801

The specific surface area and porosity of the PtAg NTAGs, the Ag aerogel, and the commercial Pt black were determined from $\mathrm{N}_{2}$ physisorption isotherms. As shown in Figure 3 (a), the

(a)

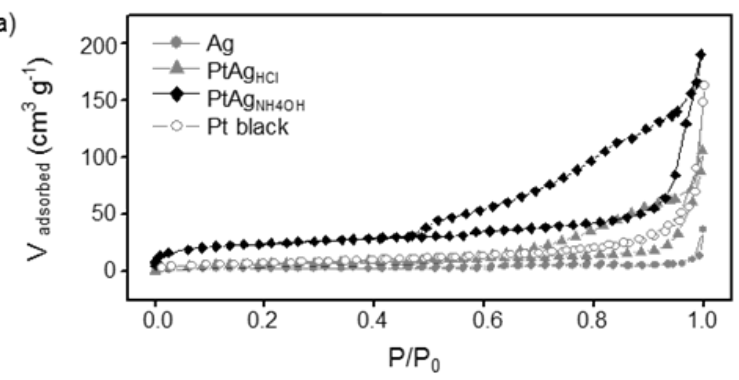

(b)

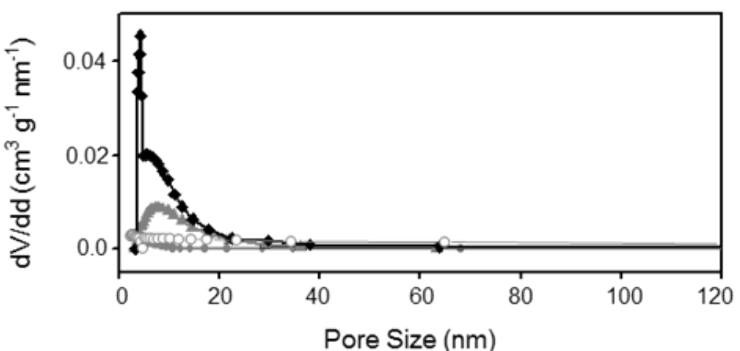

(c)

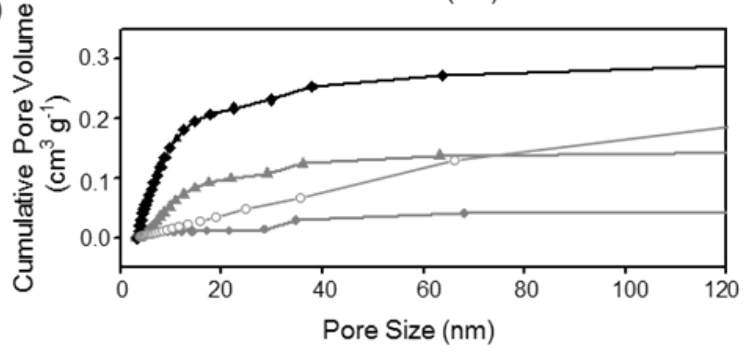

Figure 3. $\mathrm{N}_{2}$ physisorption isotherms (a), pore size distribution (b) and cumulative pore volume (c) evaluations of the $\mathrm{Ag}$ aerogel, $\mathrm{PtAg} \mathrm{HCl}$ and $\mathrm{PtAg}_{\mathrm{NH} 4 \mathrm{OH}}$ NTAGs, and the Pt black.

isotherm of the Ag aerogel is a combination of a type II and a type IV curve, similar to those for the metallic aerogels reported earlier. ${ }^{2,89}$ For the PtAg NTAGs, the isotherms are also a combination of a type IV and a type II curve, what is different is that they both show a large $\mathrm{H}_{2}$ type hysteresis loop typical for cage-like porous structures. ${ }^{31,32}$ The results consist with their hollow nanotubular structure. The Brunauer-Emmett-Teller specific surface areas $\left(\mathrm{A}_{\mathrm{BET}}\right)$ are $24.7 \mathrm{~m}^{2} \mathrm{~g}^{-1}, 83.4 \mathrm{~m}^{2} \mathrm{~g}^{-1}, 10.0 \mathrm{~m}^{2} \mathrm{~g}^{-1}$, and 30.8 
$\mathrm{m}^{2} \mathrm{~g}^{-1}$ for the PtAg $\mathrm{HCl}_{\mathrm{HCl}}$ NTAG, the PtAg $\mathrm{NH}_{4 \mathrm{OH}}$ NTAG, the Ag aerogels, and the Pt black, respectively. As shown in Figure 3 (b) and (c), the $\mathrm{PtAg}_{\mathrm{HCl}}$ and the $\mathrm{PtAg}_{\mathrm{NH} 4 \mathrm{OH}}$ NTAGs exhibit considerably more mesopores in the range of $3.20 \mathrm{~nm}$ than the $\mathrm{Ag}$ aerogel. The pore volumes of the $\mathrm{PtAg} \mathrm{HCl}\left(0.165 \mathrm{~cm}^{3} \mathrm{~g}^{-1}\right)$ and the $\mathrm{PtAg} \mathrm{NH}_{\mathrm{NHOH}}$ NTAGs $\left(0.300 \mathrm{~cm}^{3} \mathrm{~g}^{-1}\right)$ are much higher than that for the Ag aerogel $\left(0.086 \mathrm{~cm}^{3} \mathrm{~g}^{-1}\right)$, further confirming their hollow nanotubular structure. Despite the similar morphologies of the $\mathrm{PtAg}_{\mathrm{HCl}}$ and the $\mathrm{PtAg}_{\mathrm{NH} 4 \mathrm{OH}}$ NTAGs, there are obvious differences between them considering the pore size distributions, the cumulative pore volumes, and the $\mathrm{A}_{\mathrm{BET}}$. The PtAg $\mathrm{NH}_{\mathrm{NHH}}$ NTAG has more mesopores than the $\mathrm{PtAg}_{\mathrm{HCl}} \mathrm{NTAG}$, and it exhibits two dominant pore sizes at about $4.3 \mathrm{~nm}$ and $5.6 \mathrm{~nm}$, while the $\mathrm{PtAg}_{\mathrm{HCl}}$ NTAG exhibits only one dominant pore size at about $7.3 \mathrm{~nm}$. The cumulative pore volume and the $A_{B E T}$ of the PtAg ${ }_{\mathrm{NH} 4 \mathrm{OH}}$ NTAG are much higher than those of the $\mathrm{PtAg}_{\mathrm{HCl}}$ NTAG. These differences combined with the STEM-EDX results indicate that the $\mathrm{AgCl}$ residue in the $\mathrm{PtAg}_{\mathrm{HCl}} \mathrm{NTAG}$ most probably covers the small pores on the nanotube surface of this aerogel. The content of Ag before and after the $\mathrm{HNO}_{3}$ treatment of the $\mathrm{PtAg}_{\mathrm{HCl}} \mathrm{NTHG}$ did not change, but was reduced by 32\% for the $\mathrm{PtAg}_{\mathrm{NH} 4 \mathrm{OH}}$ NTHG (Table S2), further confirming the above assumption and implying that the AgCl residue may form a protective layer in the $\mathrm{PtAg}_{\mathrm{HCl}}$ NTAG.

The electrocatalytic activity of the PtAg NTAGs was tested with the model reaction of formic acid oxidation. Commercial Pt black was also investigated for comparison. Before that, all the modified electrodes were firstly cycled in $0.1 \mathrm{M} \mathrm{HClO}_{4}$ in the range of $-0.23 \mathrm{~V}$ to $1.20 \mathrm{~V}$ (vs $\mathrm{Ag} / \mathrm{AgCl}$ ) under $\mathrm{N}_{2}$ until steady-state electrode surfaces were obtained (Figure S3 and text therein), which plays the roles of electrochemical cleaning of the PtAg NTAGs surface (including removal of the $\mathrm{AgCl}$ residues),dealloying of $\mathrm{Ag}$ from the aerogel, and rearrangement of $\mathrm{Pt}$ and $\mathrm{Ag}$ atoms at the metal surface. Then the electrochemically treated electrodes were utilized for the electrocatalytic oxidation of formic acid. As is known, the formic acid oxidation can take place via dual pathways, namely the direct oxidation to $\mathrm{CO}_{2}$ by a dehydrogenation reaction (equations $\mathrm{S} 1$, reflected as $\mathrm{f} 1$ peak) and the indirect oxidation by a dehydration reaction via the poisoning $\mathrm{CO}$ intermediate (equations $\mathrm{S} 2$, reflected as $\mathrm{f}_{2}$ peak). ${ }^{21,33-35} \mathrm{As}$ shown in Figure 4 and Table S3, the metal based mass current density $\mathrm{j}_{\mathrm{f} 1}$ of the $\mathrm{PtAg}_{\mathrm{HCl}}$ and $\mathrm{PtAg}_{\mathrm{NH} 4 \mathrm{OH}}$ NTAGs are 19.0 and 9.0 times and the $\mathrm{j}_{\mathrm{f} 2}$ are 4.5 and 7.9 times higher than those of the Pt black, respectively, suggesting that both NTAGs have much higher electrocatalytic activities toward the formic acid oxidation than the Pt black. The $\mathrm{j}_{\mathrm{f} 1} / \mathrm{j}_{\mathrm{f} 2}$ for the PtAg NTAGs are also higher than that for the Pt black, indicating that the formation of the poisoning intermediate $\mathrm{CO}_{\mathrm{ads}}$ is more suppressed on the nanotubular aerogels. ${ }^{21,33,35}$

The long-term stabilities of the modified electrodes were investigated by continuous CV scans and by chronoamperometry. As shown in Figure S4, the catalytic currents of the $\mathrm{PtAg}_{\mathrm{HCl}}$ and $\mathrm{PtAg}_{\mathrm{NH} 4 \mathrm{OH}}$ NTAGs for the 1rst CV scan are 30.5 and 21.2 times higher than that of the Pt black, respectively. After that the catalytic current decreases quickly in the first 15 scans. Despite the initial faster decrease rate than that of the Pt black, the decrease slows down considerably with increasing number of scans. Over the entire range of CV scans the catalytic currents of the $\mathrm{PtAg}_{\mathrm{HCl}}$ and the $\mathrm{PtAg}_{\mathrm{NH} 4 \mathrm{OH}}$ NTAGs remain at least 13.2 times and 8.5 times that of the Pt black, respectively. As for the chronoamperometry test (Figure 4 (b)), both the PtAg NTAGs exhibit much higher initial polarization current densities and steady-state current densities than the Pt black electrode does. Notably, the current density ratios between the PtAg NTAGs and the Pt black also increase with the increase of test time (Table S4). These results further confirm the higher catalytic activity and better tolerance to the poisonous intermediate species of the PtAg NTAGs toward formic acid electrooxidation than the Pt black.

TEM was further utilized to monitor the structural stabilities of the catalysts during the electrocatalysis (Figure S5). The interconnected 3D network hierarchical porous nanotubular structure and the small nanocrystal size on the secondary network of the tube surface of the PtAg ${ }_{\mathrm{HCl}}$ NTAG remained unaltered after $200 \mathrm{CV}$ scans for the $\mathrm{HCOOH}$ electrooxidation, showing its excellent structural stability. As for the $\mathrm{PtAg}_{\mathrm{NH} 4 \mathrm{OH}} \mathrm{NTAG}$, the 3D network hierarchical porous nanotubular structure was retained, only the size of the small nanocrystals in the secondary network on the tube surface increased slightly from $\sim 2.2 \mathrm{~nm}$ to $~ 3.9 \mathrm{~nm}$. Agglomeration of Pt black is well observable both before and after electrocatalysis. 

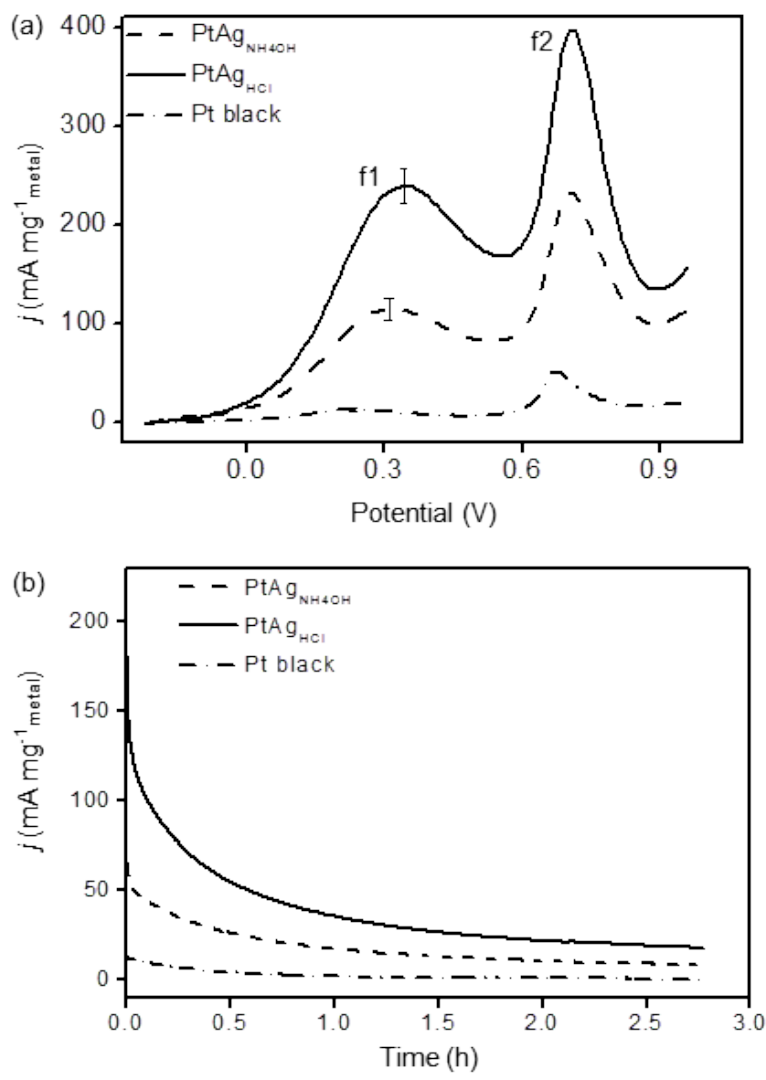

Figure 4. (a) The forward $30^{\text {th }} \mathrm{CV}$ scans of the electrodes modified with the PtAg $\mathrm{HCl}_{\mathrm{NTAG}} \mathrm{PtAg} \mathrm{NH}_{\mathrm{NOH}}$ NTAG, and Pt black in $0.1 \mathrm{M} \mathrm{HClO}_{4}-0.5 \mathrm{M} \mathrm{HCOOH}$ in the potential range of $-0.20 \mathrm{~V}$ to $0.95 \mathrm{~V}$ (vs $\mathrm{Ag} / \mathrm{AgCl}$ ) under $\mathrm{N}_{2}$. Scan rate: $50 \mathrm{mVs}^{-1}$. ' $|-|$ ' shows the standard deviation. (b) Chronoamperometry curves for formic acid oxidation at $0.18 \mathrm{~V}(\mathrm{vs} \mathrm{Ag} / \mathrm{AgCl})$ on the modified electrodes after $40 \mathrm{CV}$ scans in $0.1 \mathrm{M} \mathrm{HClO}_{4}-0.5 \mathrm{M} \mathrm{HCOOH}$ under $\mathrm{N}_{2}$.

The largely enhanced electrocatalytic activity of the PtAg aerogels toward formic acid oxidation compared with the Pt black and their excellent durability are supposed to be attributed to the following aspects. Firstly, the hierarchical porous nanotubular aerogel structure, which combines the secondary nanowire networks with a nanotubular geometry and extends to the macroscale aerogel network, provides the aerogel with favorable active sites due to the small size of the secondary network and the existence of many defects and strained sites. Secondly, the interconnected 3D network hierarchical porous nanotubular structure endows these aerogels with a large porosity, which allows for efficient mass transport through the pores and easy access to active sites. ${ }^{36}$ Furthermore, the combination of dimensions in multiple length scales and the extended surface area characteristics inhibit the dissolution and migration of the metal atoms in the aerogel as well as Ostwald ripening of the nanostructures and lead to the high durability of the aerogels in the electrocatalysis. Finally, due to the incorporation of $\mathrm{Ag}$ the number of ensembles with adjacent $\mathrm{Pt}$ atoms is decreased and, consequently, unfavorable dehydration pathways of the formic acid oxidation are suppressed. ${ }^{33}$

In this work, we demonstrate an effective strategy for designing (electro)catalysts with both good activity and durability, by combing the 1D metal nanowire structure with a nanotube geometry and further extension into 3D aerogel networks. PtAg nanotubular aerogels with hierarchical porous network structures were fabricated by the simple galvanic replacement reaction between the Ag hydrogel and the Pt precursor. The PtAg nanotubular aerogels show excellent electrocatalytic activities toward the formic acid oxidation, with the metal based mass current densities reaching 19 times that of the commercial $\mathrm{Pt}$ black, and exhibit outstanding electrochemical and structural durability during the electrocatalysis. This catalyst design strategy represents a promising direction to develop highly active and stable catalysts, and 
is of great importance in unfolding their practical applications in fuel cells, and other energy conversion and storage devices.

\section{ASSOCIATED CONTENT}

Supporting Information. Description of the Experimental methods, results of the HRTEM, and XRD investigations as well as TEM number averaged size distribution and the morphology change of the tested catalysts before and after electrocatalysis, additional electrochemical data, Tables for the contents of different components in the aerogels obtained by STEM-EDX and SEM-EDX and Tables for the summary of electrochemical results are collected in the SI. This material is available free of charge via the Internet at http://pubs.acs.org.

\section{AUTHOR INFORMATION}

\section{Corresponding Authors}

*E-mail for A.E.: alexander.eychmueller@chemie.tu-dresden.de.

*E-mail for W.L.: wei.liu@chemie.tu-dresden.de.

\section{Author Contributions}

The manuscript was written through contributions of all authors. / All authors have given approval to the final version of the manuscript. /

\section{Funding Sources}

European Research Council (ERC-2013-AdG 340419 AEROCAT), DFG-SNF (EY 16/18-1), and DFG (EY 16/10-2, EY 16/18-1 and GRK 1401). European Union Seventh Framework Programme under Grant Agreement $312483 \quad$ ESTEEM2 (Integrated Infrastructure Initiative-I3)

\section{ACKNOWLEDGMENT}

We acknowledge the support from the European Research Council (ERC-2013-AdG 340419 AEROCAT), DFG-SNF (EY 16/18-1), and DFG (EY 16/10-2, EY 16/18-1 and GRK 1401). The research leading to the STEM-HAADF and STEM-EDX results has received funding from the European Union Seventh Framework Programme under Grant Agreement 312483 - ESTEEM2 (Integrated Infrastructure Initiative-I3).

\section{REFERENCES}

(1) Tappan, B. C.; Steiner, S. A.; Luther, E. P. Nanoporous Metal Foams. Angew. Chem. Int. Ed. 2010, 49, $4544-4565$.

(2) Liu, W.; Herrmann, A.-K.; Bigall, N. C.; Rodriguez, P.; Wen, D.;Oezaslan, M.; Schmidt, T. J.; Gaponik, N.; Eychmüller, A. Noble Metal Aerogels-Synthesis, Characterization, and Application as Electrocatalysts. Acc. Chem. Res. 2015, 48, 154-162.

(3) Leventis, N.; Chandrasekaran, N.; Sotiriou-Leventis, C.; Mumtaz, A.

Smelting in the Age of Nano: Iron Aerogels. J. Mater. Chem. 2009, 19,63-65.

(4) Leventis, N.; Chandrasekaran, N.; Sadekar, A. G.; Mulik, S.; Sotiriou-Leventis, C. The Effect of Compactness on the Carbothermal Conversion of Interpenetrating Metal oxide/Resorcinol- 
Formaldehyde Nanoparticle Networks to Porous Metals and Carbides. J. Mater. Chem. 2010, 20, 74567471.

(5) Leventis, N.; Chandrasekaran, N.; Sadekar, A. G.; Sotiriou-Leventis, C.; Lu, H. One-Pot Synthesis of Interpenetrating Inorganic/Organic Networks of $\mathrm{CuO} /$ Resorcinol-Formaldehyde Aerogels: Nanostructured Energetic Materials. J. Am. Chem. Soc. 2009, 131, 4576-4577.

(6) Mahadik-Khanolkar, S.; Donthula, S.; Bang, A.; Wisner, C.; Sotiriou-Leventis, C.; Leventis, N. Polybenzoxazine Aerogels. 2. Interpenetrating Networks with Iron Oxide and the Carbothermal Synthesis of Highly Porous Monolithic Pure Iron(0) Aerogels as Energetic Materials. Chem. Mater. 2014, 26, 1318 1331.

(7) Bigall, N. C.; Herrmann, A.-K.; Vogel, M.; Rose, M.; Simon, P.; Carrillo-Cabrera, W.; Dorfs, D.; Kaskel, S.; Gaponik, N.; Eychmüller, A. Hydrogels and Aerogels from Noble Metal Nanoparticles. Angew. Chem. Int. Ed. 2009, 48, 9731-9734.

(8) Liu, W.; Herrmann, A.-K.; Geiger, D.; Borchardt, L.; Simon, F.; Kaskel, S.; Gaponik, N.; Eychmüller, A. High-Performance Electrocatalysis on Palladium Aerogels. Angew. Chem. Int. Ed. 2012, 51, 5743-5747.

(9) Liu, W.; Rodriguez, P.; Borchardt, L.; Foelske, A.; Yuan, J.; Herrmann, A.-K.; Geiger, D.; Zheng, Z.; Kaskel, S.; Gaponik, N.; Kötz, R.; Schmidt, T. J.; Eychmüller, A. Bimetallic Aerogels: High-Performance Electrocatalysts for the Oxygen Reduction Reaction. Angew. Chem. Int. Ed. 2013, 52, 9849-9852.

(10) Herrmann, A.-K.; Formanek, P.; Borchardt, L.; Klose, M.; Giebeler, L.; Eckert, J.; Kaskel, S.; Gaponik, N.; Eychmüller, A. Multimetallic Aerogels by Template-Free Self-Assembly of Au, Ag, Pt, and Pd Nanoparticles. Chem. Mater. 2014, 26, 1074-1073.

(11) Wen, D.; Herrmann, A.-K.; Borchardt, L.; Simon, F.; Liu, W.; Kaskel, S.; Eychmüller, A. Controlling the Growth of Palladium Aerogels with High-Performance toward Bioelectrocatalytic Oxidation of Glucose. J. Am. Chem. Soc. 2014, 136, 2727-2730.

(12) Wen, D.; Liu, W.; Herrmann, A.-K.; Eychmüller, A. A Membraneless Glucose/O ${ }_{2}$ Biofuel Cell Based on Pd Aerogels. Chem.-A Euro. J. 2014, 20, 4380-4385. 
(13) Zhu, C.; Wen, D.; Oschatz, M.; Holzschuh, M.; Liu, W.; Herrmann, A.-K.; Simon, F.; Kaskel, S.;

Eychmüller, A. Kinetically Controlled Synthesis of PdNi Bimetallic Porous Nanostructures with Enhanced Electrocatalytic Activity. Small 2015, 11, 1430-1434. 